\title{
Review
}

Neuro

epidemiology

\section{Prevalence of Muscular Dystrophies: A Systematic Literature Review}

\author{
Alice Theadom $^{a} \quad$ Miriam Rodrigues ${ }^{b, c}$ Richard Roxburgh ${ }^{b}$ Shiavnthi Balalla ${ }^{a}$ \\ Chris Higgins $^{c}$ Rohit Bhattacharjee ${ }^{a}$ Kelly Jones $^{a}$ Rita Krishnamurthi ${ }^{a}$ \\ Valery Feigin ${ }^{a}$ \\ ${ }^{a}$ National Institute for Stroke and Applied Neuroscience, Auckland University of Technology, ${ }^{\text {b Neurology }}$ \\ Department, Auckland City Hospital, and ' Muscular Dystrophy Association of New Zealand, Auckland, New Zealand
}

\section{Key Words}

Muscular dystrophy · Myotonic dystrophy · Epidemiology ·

Prevalence $\cdot$ Systematic review

\begin{abstract}
Background: Determining the prevalence of neuromuscular disorders for the general population is important to identify the scope of burden on society and enable comparisons with other health conditions. This systematic review aims to identify and collate the findings of studies published between 1960 and 2013 on the prevalence of all types of muscular dystrophies. Summary: Relevant articles were identified through electronic database searches and manual searches of reference lists. There were 38 articles from across 19 countries that met the inclusion criteria. The total combined prevalence for all muscular dystrophies for studies classified as having a low risk of bias ranged between 19.8 and 25.1 per 100,000 person-years. Myotonic dystrophy (0.5-18.1 per 100,000), Duchenne muscular dystrophy (1.7-4.2) and facioscapulohumeral muscular dystrophy $(3.2-4.6$ per 100,000$)$ were found to be the most common types of disorder. There was wide variation in study methodology, case ascertainment, and verification procedures and populations studied, all of which may contribute to the wide prevalence range, in
\end{abstract}

addition to the likely variation in prevalence by country. Key Messages: Greater consistency in the conduct and reporting of neuroepidemiological studies is urgently needed to enable comparisons to be made between studies, countries, and over time.

(c) 2014 S. Karger AG, Basel

\section{Introduction}

Muscular dystrophies are inherited disorders caused by mutations in a number of genes. These genetic mutations cause either a dysfunction in, or lack of, proteins that are essential for muscle cell stability, leading to progressive destruction and weakness in the muscles $[1,2]$. The term muscular dystrophy encompasses a range of disorders including Duchenne, Becker, congenital, myotonic, Emery-Dreifuss, facioscapulohumeral, oculopharyngeal, and limb-girdle muscular dystrophies [1]. Each disorder varies in severity, age of onset, pattern of inheritance, and affected muscle groups and other organs [3]. Symptoms can include muscle weakness and wasting; joint stiffness with reduced range of movement; recurrent chest infections and daytime somnolence when respiratory muscles are involved; shortness of breath and ankle

\section{KARGER}

E-Mail karger@karger.com

www.karger.com/ned
(C) 2014 S. Karger AG, Basel

0251-5350/14/0434-0259\$39.50/0
Alice Theadom, PhD, Senior Research Fellow

National Institute for Stroke and Applied Neuroscience

AUT University, 90 Akoranga Drive

Private Bag 92006, Auckland (New Zealand)

E-Mail alice.theadom@aut.ac.nz 
swelling when cardiomyopathy occurs; faints, collapses, and even sudden death when the cardiac conduction system is involved; facial weakness with drooping of the eyelids, pain, and swallowing difficulties may also occur [1]. In myotonic dystrophy not only are muscle weakness and myotonia clinical features, but nearly every system including the endocrine system is affected [4]. Across the muscular dystrophies, symptoms commonly lead to difficulties with physical activity including walking and functioning in every-day life, reducing quality of life and placing a high strain on both the individuals and their families $[5,6]$.

Diagnosis of muscular dystrophies requires a comprehensive medical history, noting particularly the distribution of weakness, age of onset, family history, and diseasespecific features. A physical examination needs to document the distribution of weakness and atrophy (face, distal, or proximal or specific muscle groups), the presence of contractures and other specific features such as myotonia. These findings together with investigations such as serum creatinine phosphokinase, electromyography, and muscle biopsy may direct testing toward a specific genetic diagnosis [7]. Prognosis varies across the muscular dystrophies with some patients experiencing mild, though usually progressive symptoms, while others experience severe disability and early mortality [1]. Advances have been made over the last decade in the treatment and management of the muscular dystrophies but there remains no cure. Current treatment aims to manage symptoms, slow progression, and prevent complications [1].

In order to ensure that information, resources, and appropriate services are available to those affected by muscular dystrophies, accurate information on the prevalence of muscular dystrophies is needed to address both the common and disease-specific needs of the different disorders. Synthesizing evidence in a systematic review helps to quantify both the burden and risk of disease across countries [8]. A systematic review of the prevalence of Duchenne and Becker muscular dystrophy has recently been undertaken, which has provided details of prevalence per 100,000 of the male population [9]. While Duchenne and Becker muscular dystrophy occurs predominantly in males, prevalence estimates need to also be available in relation to the general population to enable calculation of the scope of the burden for society. Data on the scope of burden can be critical in informing the allocation of research funds and development of new treatments. Additionally, prevalence estimates are needed for all types of the muscular dystro- phies. This systematic review aims to determine the prevalence of all muscular dystrophies within the general population.

\section{Methods}

To determine the prevalence of muscular dystrophies, a systematic literature search of Medline, CINAHL, Psychology and behavioal sciences collection, ProQuest, Scopus, Web of Science between 01/01/1960 and 30/10/2013 was conducted. Search terms included; 'muscular dystroph*' OR 'myotonic dystrophy' AND 'epidemiol*' OR 'proportion' OR 'prevalence' in the title or abstract. Hand searches of reference lists of identified articles were also conducted.

For inclusion into the systematic review, studies were required to present prevalence or data enabling calculation of crude prevalence (including number of cases identified and estimates of the denominator population) on muscular dystrophies and/or its various types. Only studies reporting on cases ascertained from a general population sample (e.g., not restricted by gender or ethnicity) were included to enable comparison with other disorders, and between populations, to ensure representativeness of the findings. Muscular dystrophy was defined as an inherited group of disorders caused by defects in the muscle membrane or supporting proteins leading to progressive weakness of the muscles [1]. Types of muscular dystrophies included in this review were dystrophinopathies (Duchenne, Becker and manifesting female carriers), myotonic dystrophy (both types 1 and 2), facioscapulohumeral, limb-girdle (all types), Emery-Dreifuss, oculpharyngeal, and congenital (all types) [10-14]. Spinal muscular atrophies and other neuromuscular disorders were not included in order to maintain a focus on disorders where the primary defect is in the muscle or its supporting membranes. Only abstracts and/or full articles published in English were considered for inclusion into the review.

Studies were excluded if they were published prior to 1960. This criteria was set as formal descriptions of many neuromuscular disorders were not established until the late 1950s and it would be difficult to make comparisons between earlier diagnoses and current diagnostic descriptions. Studies citing birth prevalence were also excluded as they more accurately reflect incidence of neuromuscular disorders among births, as opposed to prevalence in the general population. A founder effect occurs when there is a loss of genetic variation when new colonies are established from a few members of the original population resulting in extremely high prevalence [15]. Studies reporting a founder effect were therefore also excluded from the review to prevent prevalence estimates being skewed. Titles and abstracts for all citations were assessed for possible inclusion in the review. Full articles were obtained for studies meeting the inclusion criteria where possible. Duplicate publications reporting on the same data were removed.

Each identified study was classified as having a low, unclear (if insufficient information was available to determine risk) or high risk of under or overestimating prevalence. A study was assessed as having a high risk of bias for this review if the study population was restricted (e.g., <18 years), if cases were likely to be missed by the case ascertainment approaches used (e.g., household survey or reliance on clinician referrals) or if no verification of diagnosis was evident. Prevalence was calculated per 100,000 and checked for accuracy where possible, based on the data provided. 
Fig. 1. Study selection flowchart.

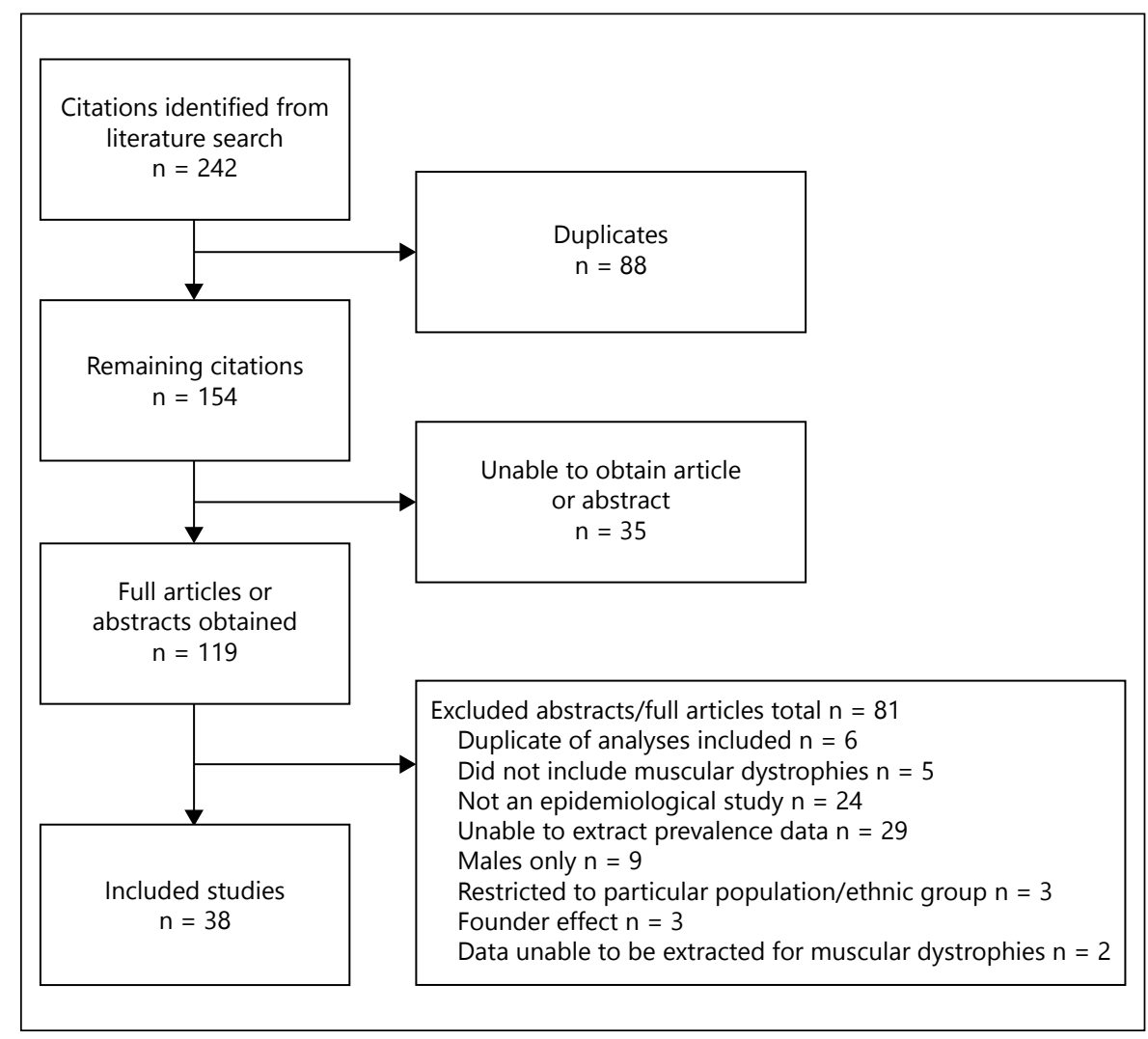

\section{Results}

The search strategy elicited a total of 242 relevant citations from across all sources. There were 38 articles that met the inclusion criteria and from which data were extracted (see fig. 1).

The included studies reported data from 19 different geographical settings across the continents of North America, Asia, Africa, Oceania, and Europe (see fig. 2). No studies were identified from South America. The included studies presented data on the prevalence of muscular dystrophies collected between 1966 and 2013. There were ten studies conducted in Italy [16-25], seven from the United Kingdom [26-32], three in Japan [33$35]$, two in Sweden [36, 37], and Canada [38, 39], and one from China [40], Croatia [41], Egypt [42], Libya [43], Netherlands [44], New Zealand [45], Norway [46], Portugal [47], Russia [48], Slovenia [49], South Africa [50], Spain [51], Taiwan [52], and the United States [53].

Characteristics of the included studies including summaries of case ascertainment and diagnostic verification procedures and potential risk of bias rating are outlined in table 1 . Of the 38 included studies, 28 presented data based on searches of medical records at hospitals and/or specialist treatment centers; seven, data from searches of national/community databases; seven, data from referrals from treating practitioners, one, data from previous research studies, and one, data from a door-to-door survey. Some studies focused specifically on certain types of muscular dystrophies, whereas others included all muscular dystrophies. The method of case ascertainment could not be determined for six studies. Only ten studies reported using more than one method of ascertaining cases. Diagnosis was verified in $71 \%$ of studies by use of clinical investigations and/or genetic analysis. In the remaining studies, it was not clear how the diagnosis was confirmed.

Fifteen studies (39.5\%) were classified as having a low risk of bias based on the predetermined criteria; two of these, from the United Kingdom, covered all dystrophies $[26,32]$. For the separate conditions, there were eight studies from four different countries that explored the prevalence of Duchenne $[16,22,26,28,32,38,49,54]$ and seven from four countries for Becker $[22,26,28,32,38$, $49,54]$. A further seven studies from five more ethnically diverse countries looked at myotonic dystrophy $[23,26$, 


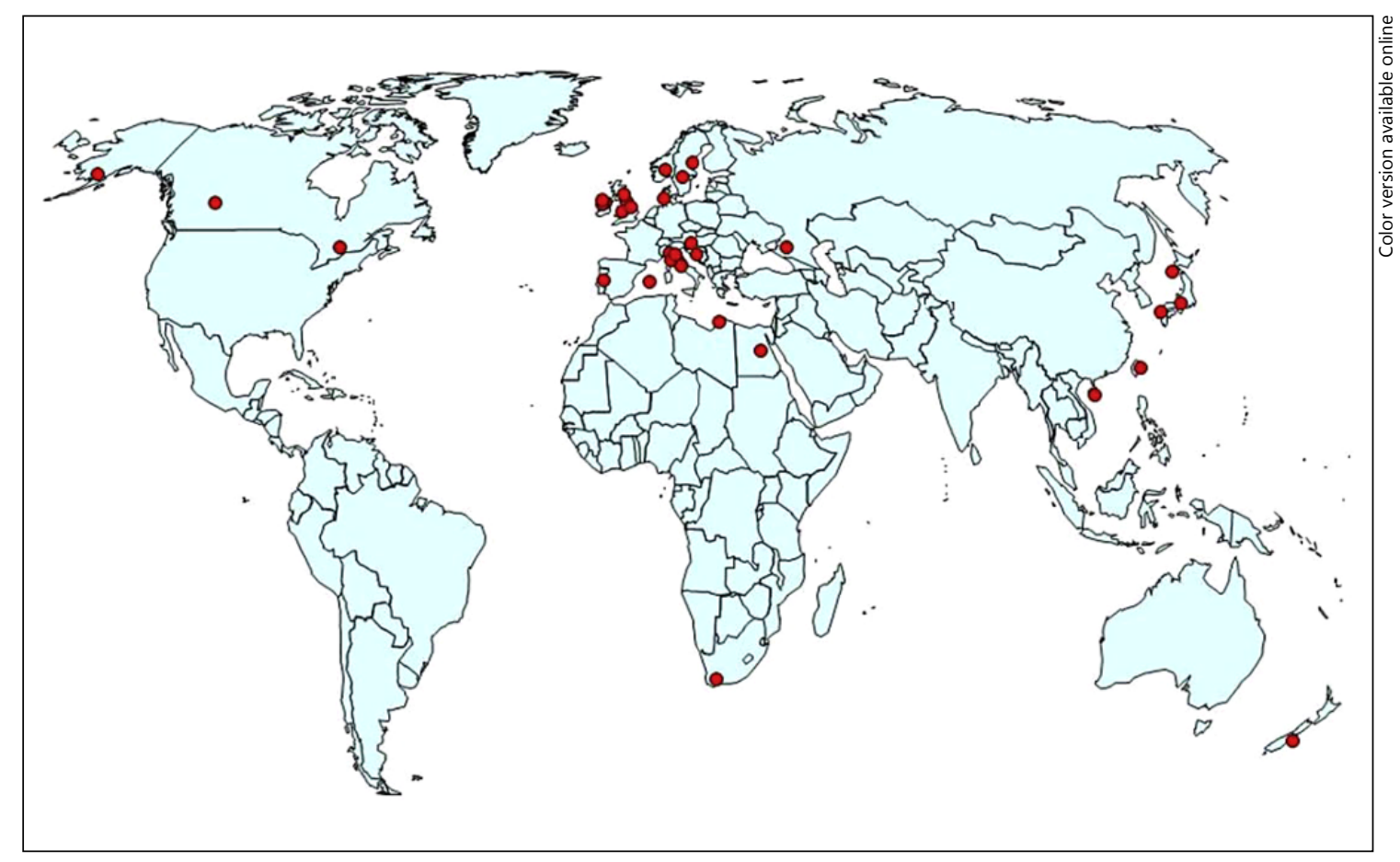

Fig. 2. Worldwide map of identified prevalence studies on muscular dystrophies.

$30,32,41,45,52]$; three studies from two countries studied facioscapulohumeral $[20,26,32]$; three studies from two countries studied limb-girdle [18, 26, 32], two studies from two countries reported on Emery-Dreifuss [26, 32], two studies from two countries $[26,32]$ reported on manifesting carriers, and one study reported on oculopharyngeal [26] and congenital muscular dystrophy [32].

Crude prevalence per 100,000 for all muscular dystrophies across the included studies ranged between 3.8 in Japan to 26.8 in Egypt (see table 2). For studies classified as having low risk of bias, the prevalence estimates narrowed revealing a prevalence range between 19.8 and 25.1 per 100,000 . Myotonic dystrophy was identified as the most prevalent muscular dystrophy across countries within the general population. Only one study presented ageadjusted prevalence [43]. No studies reported prevalence by age or gender distribution. Data on the prevalence of each type of muscular dystrophy are presented in table 2.

\section{Discussion}

The crude prevalence for all muscular dystrophies and the separate disorders was found to vary widely. However, when only the studies classified as having low risk of bias were considered there was closer agreement, yielding a best estimate of the combined prevalence of all muscular dystrophies of between 19.8 and 25.1 per 100,000, although it should be noted that both these studies were from the United Kingdom.

The prevalence range for the different types of muscular dystrophies varied substantially. For example, with myotonic dystrophy, in which studies with low risk of bias came from a wider range of countries, showed a prevalence range from 0.5 to 18.1 per 100,000 . The lowest rates were seen in the Taiwanese (0.5) and Italian (2.0) populations and the highest in Croatia with studies in British populations (or their descendants) being midway (7.111.8). Prevalence for myotonic dystrophy was particularly wide ranging between 0.5 and 18.1 per 100,000 , the reasons for which are unclear and require further investigation. Facioscapulohumeral muscular dystrophy showed a fairly consistent prevalence range of 3.2-4.6 but again only two countries were included as having studies that had a low risk of bias.

The low risk studies yielded estimates for Duchenne and Becker muscular dystrophy of 1.7-4.2 and 0.4-3.6 per 100,000 , respectively. While there are challenges in comparing findings with other estimates based only on the male population, the findings for Duchenne appear 


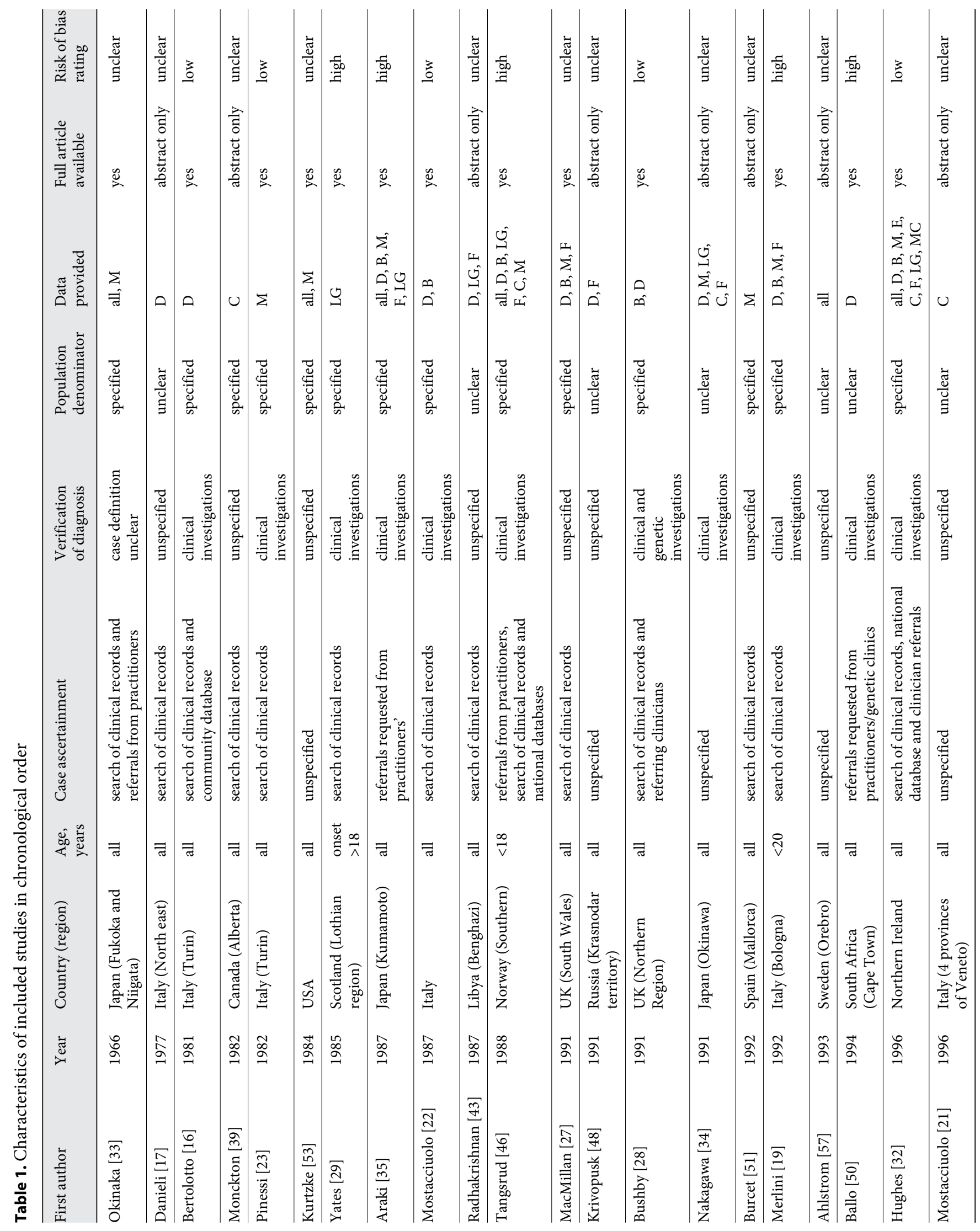




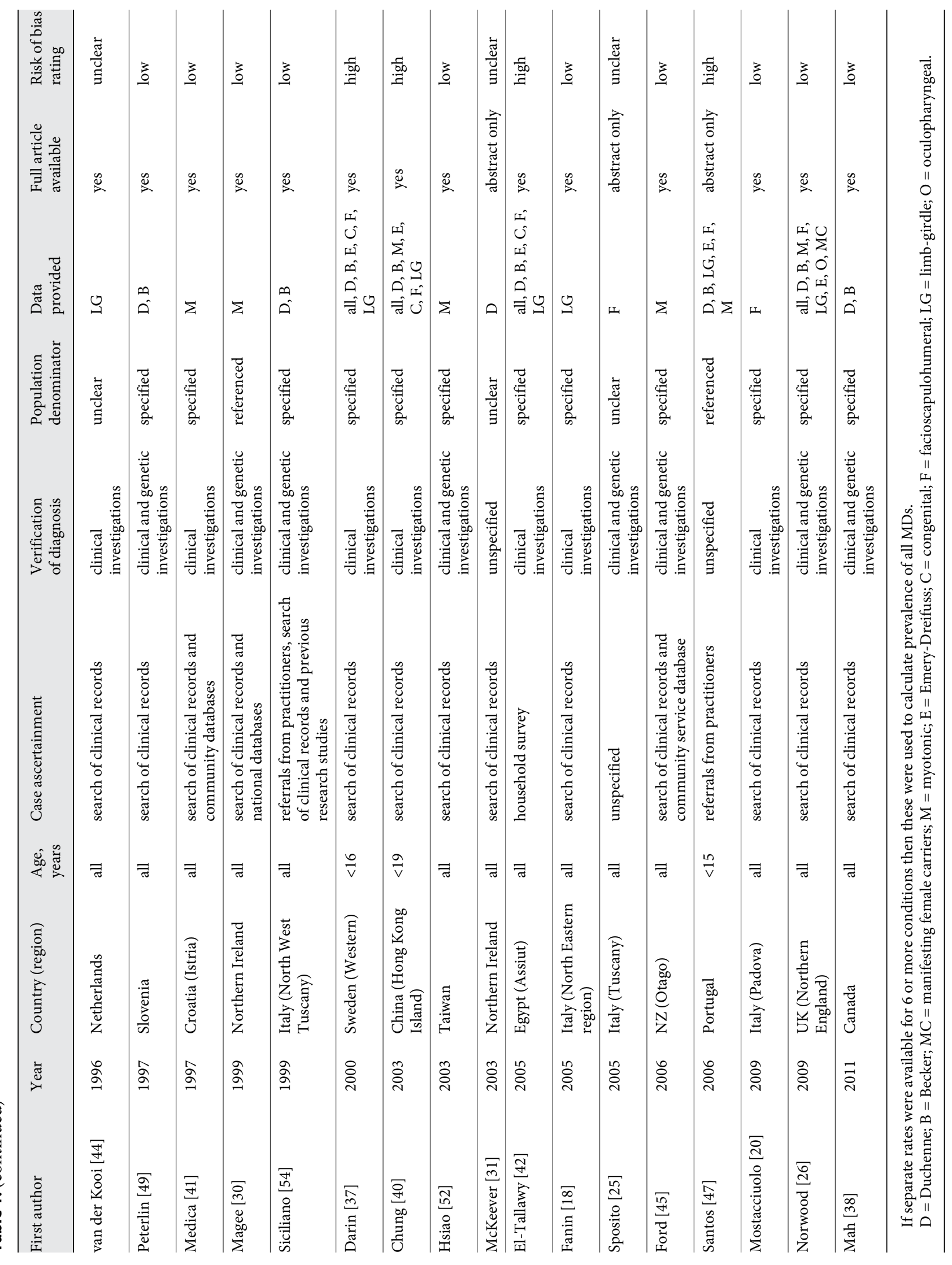




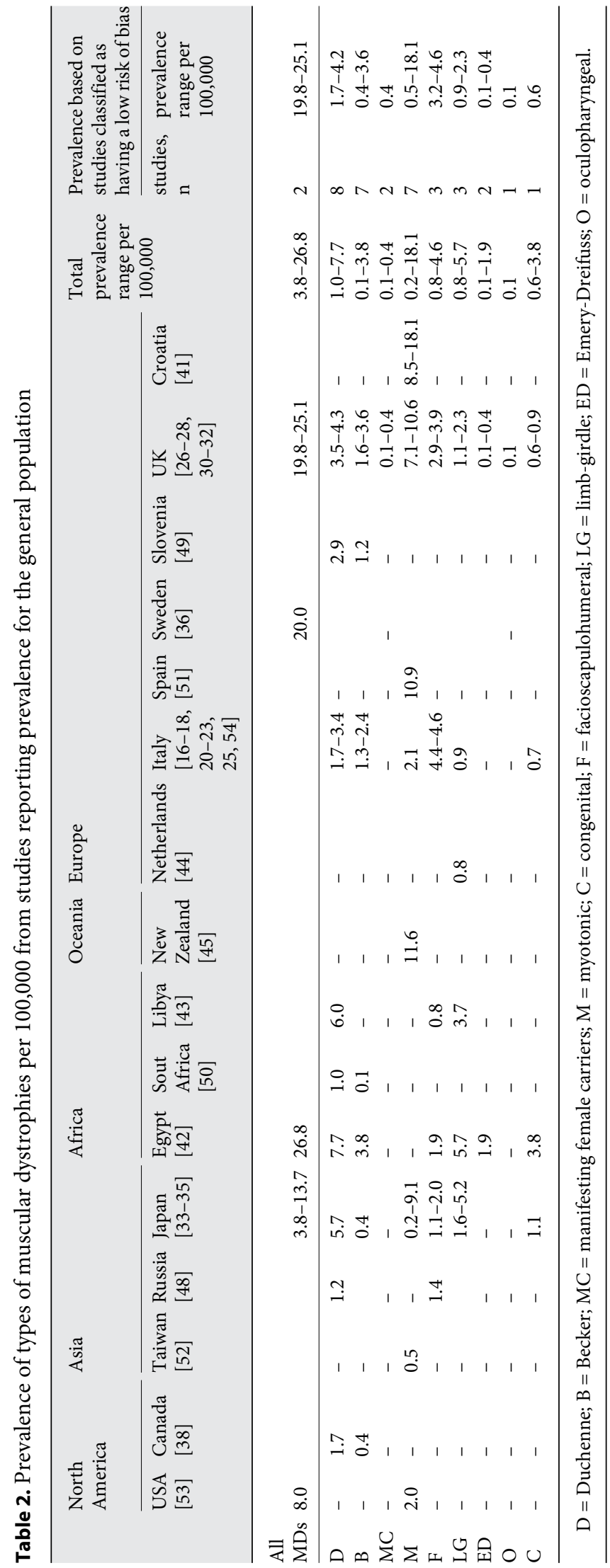

lower than the prevalence of 4.78 per 100,00 males identified by Mah et al. [9]. This is likely a reflection of the exclusion of studies restricted to males or exploring only a limited age range from this review. The prevalence of Duchenne muscular may also not fully represent the burden of the condition due to the early mortality of people affected, often before 20 years of age [12].

Comparing the results with other neurological diseases, the overall rate for muscular dystrophy is clearly lower than for conditions such as multiple sclerosis (average prevalence of $67.83 / 100,000$ ) [55] but more common than prevalence of dominantly hereditary cerebellar ataxias $(2.7$ per 100,000$)$ [56]. The impact for the affected person and their families can be devastating, particularly because muscular dystrophy can be of early onset $[5,6]$. Consequently, it remains important to have accurate prevalence rates to ensure that people affected by muscular dystrophies receive the support they need. While there was insufficient data to explore change in prevalence over time, it should be acknowledged that advances in both the accuracy and availability of diagnostic tests may have increased prevalence reported in studies exploring prevalence over the last decade.

The wide range of prevalence across all included studies may reflect differences in population dispositions between populations, particularly for myotonic dystrophy. However, the assessment of study quality suggests that the findings are also likely to reflect the differences between the epidemiological methods used and parameters for case inclusion. Although the reporting of epidemiological studies has improved over time, there are still a number of studies where information required to assess the risk of bias was not clear or where methodological approaches were used that were deemed to introduce possible bias in the study findings.

It was observed that a number of studies reported in their discussion that their results were likely to be an underestimate due to the use of case ascertainment methods used. Few studies used multiple case ascertainment methods, which allow for capture-recapture analysis of ascertainment rates. Most studies restricted case ascertainment to a search of hospital records, which is likely to miss patients who do not require further medical treatment. It was also difficult to determine in a number of studies whether cases that were believed to have a muscular dystrophy but were awaiting confirmation from a diagnostic test or clinical investigation were included in the prevalence estimates or not. A key finding of this review is that based on the wide variation in prevalence and between methodologies in previous research, standardized 
Table 3. Suggested recommendations for the conduct of epidemiological studies on muscular dystrophies

\begin{tabular}{ll}
\hline Domains & Core criteria \\
\hline Standard definitions & - Muscular dystrophy and it types are defined \\
& $-\quad$ Requirements for meeting inclusion criteria are defined (including diagnostic standards and \\
& verification requirements) \\
\hline Standard methods & Multiple population-based case ascertainment methods used including searches of medical \\
& records, hospitals, referrals from specialists, self-referrals, community and national databases \\
& with duplicates removed after cross-checking
\end{tabular}

procedures for the conduct and reporting of epidemiological studies in this area are needed. There are no known guidelines for the conduct of epidemiological studies in neuromuscular conditions and therefore some recommendations for epidemiological studies in this field are proposed based on the findings of this systematic review (table 3).

While studies were presented from a range of countries across the world, there were no studies identified that explored the prevalence of muscular dystrophies in South America. Additionally, there was only one study conducted in Oceania, which focused on one type, myotonic dystrophy, in a relatively low-populated area of New Zealand. This highlights gaps in the current research literature. Furthermore, only one of the included studies reported age-adjusted prevalence, with no studies reporting age-specific prevalence sufficient to derive pooled age-adjusted prevalence estimates. Although presenting breakdowns of estimates can be problematic for disorders that are relatively rare, it is important to adjust for differences in population characteristics, for instance, in countries with particularly high proportions of young people. Age-adjusted prevalence could be provided in mid-decade age bands rather than five or 10 year age bands (more commonly reported in epidemiological studies) to increase the number of cases per band for these disorders. There is also a need for studies to describe how the area of the population studied reflects the overall population characteristics of the country as a whole to inform how representative the findings of the study can be. Prevalence by ethnicity is also recommended but may be restricted by low case numbers.

Although all efforts were made to identify and obtain all articles relevant to the systematic review, the authors acknowledge the possibility that not all studies were identified and that the findings do not reflect the early mortality or late onset of different types of disorders. The aim of this review was to determine the prevalence of all muscular dystrophies; however, the unique characteristics of disorders within the muscular dystrophies present some challenges. For example, in order to enable comparisons with other neurological disorders, the review was limited to studies exploring prevalence within the general population. However, it is noted that for X-linked disorders such as Duchenne and Becker muscular dystrophy that occur mainly in males, this approach may have excluded some studies exploring prevalence in the male population only. It is suggested that for $\mathrm{X}$-linked disorders that in addition to the recommendations outlined in table 3, prevalence should be reported for both males only and total population to enable meaningful comparison with other disorders.

This review has provided an overview of prevalence of the muscular dystrophies, and also identified a number of challenges in conducting epidemiological studies within this field. A summary of recommendations for the conduct of future studies on the prevalence of muscular dys- 
trophies are proposed in table 3 to address some of the unique challenges that present within this field of neuroepidemiology.

\section{Conclusion}

The prevalence of muscular dystrophies as a group was found to be between 19.8 and 25.1 per 100,000 person years. Myotonic dystrophy (0.5-18.1 per 100,000$)$, Duchenne muscular dystrophy (1.7-4.2 per 100,000) and facioscapulohumeral muscular dystrophy (3.2-4.6 per
$100,000)$ were found to be the most common types of disorder. Wide diversity between case ascertainment and verification of diagnosis suggests the need for standards on conducting and reporting studies on the prevalence of muscular dystrophies to facilitate comparison between disorders, countries, and over time.

\section{Acknowledgments and Funding}

We thank the Neuromuscular Research Foundation Trust and Richdale Charitable Trust for funding this systematic review.

\section{References}

$\checkmark 1$ Mercuri E, Muntoni F: Muscular dystrophies. Lancet 2013;381:845-860.

2 McNally EM, Pytel P: Muscle diseases: the muscular dystrophies. Annu Rev Pathol 2007; 2:87-109.

3 Mercuri E, Muntoni F: Muscular dystrophy: new challenges and review of the current clinical trials. Curr Opin Pediatr 2013;25:701707.

4 Turner C, Hilton-Jones D: The myotonic dystrophies: diagnosis and management. J Neurol Neurosurg Psychiatry 2010;81:358367.

5 Graham CD, Rose MR, Grunfeld EA, Kyle $\mathrm{SD}$, Weinman J: A systematic review of quality of life in adults with muscle disease. J Neurol 2011;258:1581-1592.

6 Boyer F, Drame M, Morrone I, Novella JL: Factors relating to carer burden for families of persons with muscular dystrophy. J Rehabil Med 2006;38:309-315.

7 Emery AE: Muscular dystrophy into the new millennium. Neuromuscul Disord 2002;12: 343-349.

8 Fiest KM, Pringsheim T, Patten SB, Svenson LW, Jette N: The role of systematic reviews and meta-analyses of incidence and prevalence studies in neuroepidemiology. Neuroepidemiology 2014;42:16-24.

>9 Mah JK, Korngut L, Dykeman J, Day L, Pringsheim T, Jette $\mathrm{N}$ : A systematic review and meta-analysis on the epidemiology of Duchenne and Becker muscular dystrophy. Neuromuscul Disord 2014;24:482-491.

10 Lemmers RJ, O'Shea S, Padberg GW, Lunt PW, van der Maarel SM: Best practice guidelines on genetic diagnostics of Facioscapulohumeral muscular dystrophy: workshop 9th June 2010, LUMC, Leiden, The Netherlands. Neuromuscul Disord 2012;22:463-470.

-11 Tawil R, van der Maarel S, Padberg GW, van Engelen BG: 171st ENMC international workshop: standards of care and management of facioscapulohumeral muscular dystrophy. Neuromuscul Disord 2010;20:471-475.
${ }_{12}$ Bushby K, Finkel R, Birnkrant DJ, Case LE, Clemens PR, Cripe L, Kaul A, Kinnett K, McDonald C, Pandya S, et al: Diagnosis and management of Duchenne muscular dystrophy, part 1: diagnosis, and pharmacological and psychosocial management. Lancet Neurol 2010;9:77-93.

13 Wang CH, Bonnemann CG, Rutkowski A, Sejersen T, Bellini J, Battista V, Florence JM, Schara U, Schuler PM, Wahbi K, et al: Consensus statement on standard of care for congenital muscular dystrophies. J Child Neurol 2010;25:1559-1581.

14 Turner C, Hilton-Jones D, Lochmüller H, Hanna MG: MRC Centre for Neuromuscular Diseases 1st (1st December 2010), and 2nd (2nd May 2012) myotonic dystrophy workshops, London, UK and the myotonic dystrophy standards of care and national registry meeting, Newcastle, UK July 2011. Neuromuscul Disord 2013;23:1069-1080.

15 Mayr E: Systematics and the Origin of Species from the Viewpoint of a Zoologist, vol 237. New York, Columbia University, 1942.

16 Bertolotto A, De Marchi M, Doriguzzi C, Mongini T, Monnier C, Palmucci L, Schiffer D, Verzé L: Epidemiology of Duchenne muscular dystrophy in the province of Turin. Ital J Neurol Sci 1981;2:81-84.

17 Danieli GA, Mostacciuolo ML, Bonfante A, Angelini C: Duchenne muscular dystrophy. A population study. Hum Genet 1977;35:225231.

18 Fanin M, Nascimbeni AC, Fulizio L, Angelini $\mathrm{C}$ : The frequency of limb girdle muscular dystrophy $2 \mathrm{~A}$ in northeastern Italy. Neuromuscul Disord 2005; 15:218-224.

19 Merlini L, Stagni SB, Marri E, Granata C: Epidemiology of neuromuscular disorders in the under-20 population in Bologna Province, Italy. Neuromuscul Disord 1992;2:197-200.

20 Mostacciuolo ML, Pastorello E, Vazza G, Miorin M, Angelini C, Tomelleri G, Galluzzi G, Trevisan CP: Facioscapulohumeral muscular dystrophy: epidemiological and molec- ular study in a north-east Italian population sample. Clin Genet 2009;75:550-555.

21 Mostacciuolo ML, Miorin M, Martinello F, Angelini C, Perini P, Trevisan CP: Genetic epidemiology of congenital muscular dystrophy in a sample from north-east Italy. Hum Genet 1996;97:277-279.

22 Mostacciuolo ML, Lombardi A, Cambissa V, Danieli GA, Angelini C: Population data on benign and severe forms of X-linked muscular dystrophy. Hum Genet 1987;75:217-220.

23 Pinessi L, Bergamini L, Cantello R, Di Tizio C: Myotonia congenita and myotonic dystrophy: descriptive epidemiological investigation in Turin, Italy (1955-1979). Ital J Neurol Sci 1982;3:207-210.

24 Siciliano G, Manca M, Gennarelli M, Angelini C, Rocchi A, Iudice A, Miorin M, Mostacciuolo M: Epidemiology of myotonic dystrophy in Italy: re-appraisal after genetic diagnosis. Clin Genet 2001;59:344-349.

25 Sposìto R, Pasquali L, Galluzzi F, Rocchi A, Solito B, Soragna D, Tupler R, Siciliano G: Facioscapulohumeral muscular dystrophy type 1A in northwestern Tuscany: a molecular genetics-based epidemiological and genotypephenotype study. Genet Test 2005;9:30-36.

26 Norwood FL, Harling C, Chinnery PF, Eagle M, Bushby K, Straub V: Prevalence of genetic muscle disease in Northern England: indepth analysis of a muscle clinic population. Brain 2009;132:3175-3186.

27 MacMillan JC, Harper PS: Single-gene neurological disorders in South Wales: an epidemiological study. Ann Neurol 1991;30:411-414.

28 Bushby KM, Thambyayah M, Gardner-Medwin D: Prevalence and incidence of Becker muscular dystrophy. Lancet 1991;337:10221024.

29 Yates JR, Emery AE: A population study of adult onset limb-girdle muscular dystrophy. J Med Genet 1985;22:250-257.

30 Magee A, Nevin NC: The epidemiology of myotonic dystrophy in Northern Ireland. Community Genet 1999;2:179-183. 
31 McKeever K, Magee A: Epidemiology and genetics of Duchenne muscular dystrophy in Northern Ireland. Am J Hum Genet 2003;73: 373.

32 Hughes MI, Hicks EM, Nevin NC, Patterson $\mathrm{VH}$ : The prevalence of inherited neuromuscular disease in Northern Ireland. Neuromuscul Disord 1996;6:69-73.

33 Okinaka S, Reese HH, Katsuki S, Ueki K, Kuroiwa Y, Araki S, Shiraki H, Kurland LT: The prevalence of multiple sclerosis and other neurological diseases in Japan. Acta Neurol Scand 1966;42:68-76.

34 Nakagawa M, Nakahara K, Yoshidome H, Suehara M, Higuchi I, Fujiyama J, Nakamura A, Kubota R, Takenaga S, Arahata K, et al: Epidemiology of progressive muscular dystrophy in Okinawa, Japan. Classification with molecular biological techniques. Neuroepidemiology 1991;10:185-191.

35 Araki S, Uchino M, Kumamoto T: Prevalence studies of multiple sclerosis, myasthenia gravis, and myopathies in Kumamoto district, Japan. Neuroepidemiology 1987;6: 120-129.

-36 Ahlström G, Gunnarsson LG, Leissner P, Sjödén PO: Epidemiology of neuromuscular diseases, including the postpolio sequelae, in a Swedish county. Neuroepidemiology 1993; 12:262-269.

37 Darin N, Tulinius M: Neuromuscular disorders in childhood: a descriptive epidemiological study from western Sweden. Neuromuscul Disord 2000;10:1-9.

-38 Mah JK, Selby K, Campbell C, Nadeau A, Tarnopolsky M, McCormick A, Dooley JM, Kolski H, Skalsky AJ, Smith RG, et al: A population-based study of dystrophin mutations in Canada. Can J Neurol Sci 2011;38:465-474.
39 Monckton G, Hoskin V, Warren S: Prevalence and incidence of muscular dystrophy in Alberta, Canada. Clin Genet 1982;21:19-24.

40 Chung B, Wong V, Ip P: Prevalence of neuromuscular diseases in Chinese children: a study in southern China. J Child Neurol 2003; 18:217-219.

41 Medica I, Marković D, Peterlin B: Genetic epidemiology of myotonic dystrophy in Istria, Croatia. Acta Neurol Scand 1997;95: 164-166.

42 El-Tallawy HN, Khedr EM, Qayed MH, Helliwell TR, Kamel NF: Epidemiological study of muscular disorders in Assiut, Egypt. Neuroepidemiology 2005;25:205-211.

43 Radhakrishnan K, El-Mangoush MA, Gerryo SE: Descriptive epidemiology of selected neuromuscular disorders in Benghazi, Libya. Acta Neurol Scand 1987;75:95-100.

-44 van der Kooi AJ, Barth PG, Busch HF, de Haan R, Ginjaar HB, van Essen AJ, van Hooff LJ, Höweler CJ, Jennekens FG, Jongen P, et al: The clinical spectrum of limb girdle muscular dystrophy. A survey in The Netherlands. Brain 1996;119:1471-1480.

45 Ford C, Kidd A, Hammond-Tooke G: Myotonic dystrophy in Otago, New Zealand. N Z Med J 2006;119:U2145.

46 Tangsrud SE, Halvorsen S: Child neuromuscular disease in southern Norway. Prevalence, age and distribution of diagnosis with special reference to 'non-Duchenne muscular dystrophy'. Clin Genet 1988;34:145-152.

-47 Santos MA, Fineza I, Moreno T, Cabral P, Ferreira JC, Silva RL, Vieira JP, Moreira A, Dias A, Calado E, et al: Epidemiology of neuromuscular disorders in Portugal at pediatric age. Neuromuscul Disord 2006;16:703.

48 Krivopusk ME: The clinico-epidemiological aspects of hereditary neuromuscular diseases in the Krasnodar territory. Zh Nevropatol Psikhiatr Im S S Korsakova 1991;91:3-5.
49 Peterlin B, Zidar J, Meznaric-Petrusa M, Zupancic N: Genetic epidemiology of Duchenne and Becker muscular dystrophy in Slovenia. Clin Genet 1997;51:94-97.

50 Ballo R, Viljoen D, Beighton P: Duchenne and Becker muscular dystrophy prevalence in South Africa and molecular findings in 128 persons affected. S Afr Med J 1994;84:494497.

51 Burcet J, Cañellas F, Cavaller G, Vich M: Epidemiologic study of myotonic dystrophy on the island of Mallorca. Neurologia 1992;7:6164.

52 Hsiao KM, Chen SS, Li SY, Chiang SY, Lin HM, Pan H, Huang CC, Kuo HC, Jou SB, Su $\mathrm{CC}$, et al: Epidemiological and genetic studies of myotonic dystrophy type 1 in Taiwan. Neuroepidemiology 2003;22:283-289.

53 Kurtzke JF: Neuroepidemiology. Ann Neurol 1984;16:265-277.

54 Siciliano G, Tessa A, Renna M, Manca ML, Mancuso M, Murri L: Epidemiology of dystrophinopathies in North-West Tuscany: a molecular genetics-based revisitation. Clin Genet 1999;56:51-58.

55 Wade BJ: Spatial analysis of global prevalence of multiple sclerosis suggests need for an updated prevalence scale. Mult Scler Int 2014; 2014:124578.

56 Ruano L, Melo C, Silva MC, Coutinho P: The global epidemiology of hereditary ataxia and spastic paraplegia: a systematic review of prevalence studies. Neuroepidemiology 2014; 42:174-183.

57 Ahlstrom G, Gunnarsson LG, Leissner P, Sjoden PO: Epidemiology of neuromuscular diseases, including the postpolio sequelae, in a Swedish county. Neuroepidemiology 1993; 12:262-269. 